\title{
Influencia de la red social "Instagram” en la configuración de un nuevo imaginario colectivo entre los adolescentes del Liceo Abdón Calderón, estado Carabobo
}

\author{
Influence of the social network "Instagram" in the configuration of a new \\ collective imaginary among the adolescents of the Abdón Calderón High \\ School, Carabobo state
}

Kenny Colmenares

kanovix@gmail.com

Universidad de Carabobo

\author{
Johana Márquez \\ caroljohanna54@gmail.com
}

\section{RESUMEN}

El presente trabajo surge debido al espacio y tiempo que le dedican los adolescentes a las Redes Sociales como "Instagram y la preocupación por lo que esto genera en la configuración de un nuevo imaginario colectivo en estos jóvenes. La investigación tuvo como objetivo analizar y describir la Influencia de la red social "Instagram" en la configuración de un nuevo imaginario colectivo entre los adolescentes del Liceo Abdón Calderón del Municipio Naguanagua del Estado Carabobo. La investigación es de tipo transversal, bajo un diseño descriptivo, la técnica utilizada fue una encuesta tipo cerrada y como instrumento un cuestionario, los resultados obtenidos en relación a la encuesta aplicada, arrojaron que tan solo un $12 \%$ de los estudiantes utilizan la Red Social como "Instagram", es decir, tiene muy poca influencia en la configuración de un nuevo imaginario colectivo entre los adolescentes del Liceo Abdón Calderón del Municipio Naguanagua del Estado Carabobo. Se pudo concluir que el nivel de uso del Instagram no es tan influyente como la red social Facebook en el imaginario colectivo de estos adolescentes objeto de estudio ya que gran parte de los mismos de mayor uso a esta red social y no al Instagram, quizás por la variedad con la que la red social Facebook fue creada, también es importante destacar que la misma es más utilizadas por hembras que por los varones.

Palabras clave: Red Social; Imaginario Colectivo, Instagram

\section{ABSTRACT}

The present work arises due to the space and time that adolescents dedicate to Social Networks such as "Instagram and the concern for what this generates in the configuration of a new collective imagination in these young people. The research aimed to analyze and describe the influence of the social network "Instagram" in the configuration of a new collective imaginary among the adolescents of the Abdón Calderón High School of the Naguanagua Municipality of the Carabobo State. The research is of a transversal type, under a descriptive design, the technique used was a closed type survey and as a questionnaire instrument, the results obtained in relation to the applied survey, showed that only $12 \%$ of the students use the Social Network as "Instagram", that is, it has very little influence on the configuration of a new collective imagination among the adolescents of the Abdón Calderón High School in the Naguanagua Municipality of Carabobo State. It could be concluded that the level of use of Instagram is not as influential as the social network Facebook in the collective imagination of these adolescents under study since much of them are most used to this social network and not to Instagram, perhaps because the variety with which the social network Facebook was created, it is also important to note that it is more used by females than by males.

Key words: Social Network, Collective Imaginary, Instagram 


\section{INTRODUCCIÓN}

En la actualidad, las redes sociales poseen una influencia inconmensurable, tal que es imposible predecir la influencia que adquieren los mensajes que por ellas circulan, desde tendencias comerciales, hasta polémicas políticas, nos encontramos frente a un campo sin ley donde todo es libre y permitido. Es en este mundo virtual sin ley en donde los jóvenes se adentran antes de siquiera tener un concepto individual de sí mismos bien definido, y esto causa que se pierdan en la marea informática incesante, adquiriendo un concepto de identidad trastornado y discrepando esto de la realidad física a la cual se enfrentan en las aulas de clases o en su inmediato entorno social.

Lo anteriormente mencionado es el epitafio de la problemática a manejar en el presente trabajo, particularmente se hace énfasis en la red social Instagram por ser esta la más "reciente" y la de mayor impacto en la juventud a la cual se le destina el presente trabajo de investigación. Entre los objetivos que se han de cumplir, se encuentran principalmente el estudio, contraste y análisis de la influencia de esta red social, así como las consecuencias del uso intensivo de la misma.

Para cumplir con los objetivos planteados se manejó la encuesta en una investigación de tipo transversal, la cual se realiza a los jóvenes de 12 a 16 años de edad en la institución Abdón calderón, de esta manera se puede evaluar la influencia de esta red social en los jóvenes que se encuentran en la etapa más crítica del autoconocimiento.

Las Ciencias Sociales agrupan a algunas de las disciplinas científicas, que de un modo u otro están relacionadas con el estudio de las actividades humanas y la conducta social que dichas actividades originan en ciertos individuos. La Sociología por ejemplo intenta analizar los patrones de comportamiento cultural de las personas o grupos sociales.
Otra disciplina es la Psicología Social que estudian los procesos cognitivos y mentales que tiene efecto sobre los individuos y las comunidades en ciertas condiciones.

Las llamadas redes sociales como nuevo fenómeno cultural influyente son estructuras digitales que se componen de un conjunto de organizaciones comerciales las cuales están relacionadas entre sí de acuerdo a un criterio eminentemente mercantil pero que plantean como finalidad conseguir una supuesta comunicación global que serviría para enlazar a grupos humanos alejados y apartados entre sí y con los grandes conglomerados humanos.

En su lugar dichas empresas de la comunicación, solo logran fomentar en la población global la más absoluta ignorancia a través del manejo diferenciado y sesgado de la información, divulgando solo aquella que le interesa popularizar y que sirve para generar nuevas tendencias culturales que estimulan falsas sensaciones de alegría y emoción. Todo esto con el único propósito de establecer nuevos hábitos de consumo dentro de la población y de manera muy particular en los sectores más jóvenes ya que podemos apreciar como durante los últimos diez años han surgido y se han fortalecido a escala mundial un conjunto de nuevos canales digitales de interacción social en donde la inmensa mayoría de los usuarios están ubicados entre los 12 y 16 años aproximadamente.

Se puede apreciar como sitios digitales como Facebook, Twitter, WhatsApp e Instagram lejos de promover el conocimiento y la reflexión solo logra persuadir a través de una indetenible búsqueda del placer individual. El sujeto alienado promedio no está formado para la búsqueda de la verdad como principio esencial de la existencia humana, sino que por el contrario este es estimulado hacia una búsqueda irracional del éxito y la satisfacción individual. 
Este planteamiento se hace por la inquietud que se hacen a través de los nuevos medios de comunicación digitales, debido a se empiezan a programar de forma sistemática a los niños y niñas desde la escuela para lograr establecer un consumidor inconsciente e irracional el cual no se prepara para mirar y entender el mundo que le rodea, sino para mirarse solo a sí mismo en una eterna duda y confusión logrando con esto apartarlo del mundo real.

Morín (1990) en su concepto de imaginario colectivo lo designa como "El conjunto de mitos y símbolos que en cada momento funciona efectivamente como de $<<$ mente $>>$ social colectiva. Esta es alimentada, tanto en su dimensión real como en su dimensión imaginaria que se retroalimenta de una forma cuasi religiosa por los medios de comunicación y se identifica en los productos de consumo y las personalidades mediáticas, en donde el amor, el tiempo, la juventud, el héroe, las catástrofes y desgracias funcionan como su imaginario negativo.

Es a partir de esta concepción se pudo deducir, como estas redes sociales han logrado introducir cambios importantes dentro del imaginario colectivo del adolescente venezolanos y que se articula con el 4to objetivo del plan de la patria que es la conformación de un mundo multicéntrico y pluripolar en el que se plantea la necesidad de seguir sumando fuerzas para desmontar el sistema neocolonial de dominación. Es por ello que creemos que sería a través de la Sociología la vía más propicia para tratar de entender como ha sido el efecto de estos canales de comunicación en la población venezolana más joven durante los últimos diez años y su impacto en su cultural.

Es importante mencionar que el uso de Redes Sociales como Instagram ha ayudado a transformar de cierta forma el imaginario colectivo de los jóvenes venezolanos que tienen edades comprendidas entre los 12 y 16 años, debido a que ha generado una fuerte dependencia entre este canal digital y ese grupo etario en particular, ya que se cree que la misma ha estimulado artificialmente una fantasía permanente de autocomplacencia manifestada en un constante exhibicionismo individualizado asociado al uso continuo de imágenes y modelos. Simbología que ha ayudado a perfilar toda una nueva estructura comunicacional, esto ha tenido un impacto definitivo en su cosmovisión y han logrado instaurar nuevos patrones de conducta.

Sumado a lo anterior también se encuentra con la falta casi absoluta de supervisión por parte de padres y representantes de estos adolescentes y lo más peligroso, está representado por el enorme rezago tecnológico manifestado por los docentes hacia el uso y manejo de las nuevas y múltiples herramientas tecnológicas comunicacionales. Junto a este nuevo fenómeno nos encontramos con una enorme y cada vez más preocupante desintegración familiar la cual ha venido generando una ausencia casi total de los padres, ausencia que se nota mucho más aun durante el difícil proceso de la formación del joven. Esto y el fácil acceso que tienen los adolescentes a la nueva tecnología hace más sencillo está alteración permanente en su imaginario colectivo.

De acuerdo con lo mencionado, esta investigación se planteó como Objetivo General el analizar la Influencia de la red social "Instagram" en la configuración de un nuevo imaginario colectivo entre los adolescentes del Liceo Abdón Calderón del Municipio Naguanagua del Estado Carabobo, además de describir la Influencia de la red social "Instagram" en la configuración de un nuevo imaginario colectivo en los adolescentes, determinando para ello la Influencia de la red social "Instagram" en la configuración de un nuevo imaginario 
colectivo entre los adolescentes del Liceo Abdón Calderón del Municipio Naguanagua del Estado Carabobo.

\section{MÉTODO}

Para poder evaluar los objetivos planteados en este estudio acerca del uso de la Red Social Instagram, fue considerado el enfoque cuali-cuantitativo, se trata de un diseño descriptivo, de tipo transversal. Por lo tanto, se contó con una población aproximada de 1300 jóvenes estudiantes en la U.E Abdón Calderón, ubicada en la Urbanización La Vivienda del Municipio Naguanagua del Estado Carabobo. El estudio consideró la participación de 25 estudiantes pertenecientes al Liceo Abdón Calderón, del Municipio Naguanagua del Estado Carabobo cuyas edades fluctuaban entre 12 y 16 años de edad.

Se diseñó un cuestionario compuesto por 5 ítems, con preguntas relacionadas a los objetivos planteados sobre el uso de la Red social Instagram y si este configura el imaginario colectivo, en el Liceo Abdón Calderón, del Municipio Naguanagua del Estado Carabobo.

En tal sentido, el instrumento fue aplicado a la escala de Eklöf y Johansson basado en un cuestionario de orden cerrado, a través de la confiablidad, mediante la aplicación del coeficiente de Cronbach es de 0,88 de grado bueno, lo que indica que cada vez se aplique las mismas preguntas a los mismos estudiantes de la U.E Abdón Calderón se tendrá las mismas respuestas.
Ahora bien, para Torres (2017), las encuestas son instrumentos de investigación descriptivas que precisan identificar a priori las preguntas a realizar, las personas seleccionadas en una muestra representativa de la población, especificar las respuestas y determinar el método empleado para recoger la información que se vaya obteniendo. Este instrumento nos permitió indagar entre los estudiantes en edades comprendidas entre 12 y 16 años de la U.E Abdón Calderón, ubicada en la Urbanización La Vivienda del Municipio Naguanagua del Estado Carabobo cual ha sido el impacto cultural generado a través del uso de esta red social y si la misma ha ayudado en la configuración de una nueva forma de entender la realidad que les rodea actualmente.

\section{RESULTADOS Y DISCUSIÓN}

\section{Con relación a la frecuencia mayor en el uso en las redes sociales}

Queda demostrado que los estudiantes de la U. E. Abdón Calderón, utilizan con mayor frecuencia la red social Facebook, dejando en segundo lugar la red social Instagram (nuestro objeto de estudio). Sin embargo, es importante destacar que ambas redes sociales pertenecen a la misma empresa; por lo que podríamos pensar que una tiene mayor influencia como imaginario colectivo que la otra red social, probablemente por el formato en que está diseñado Facebook, además se puede notar que las mujeres la usan más que los hombres. 


\section{Ítem 1}

¿Cual de las siguientes redes sociales usas con mayor frecuencia?

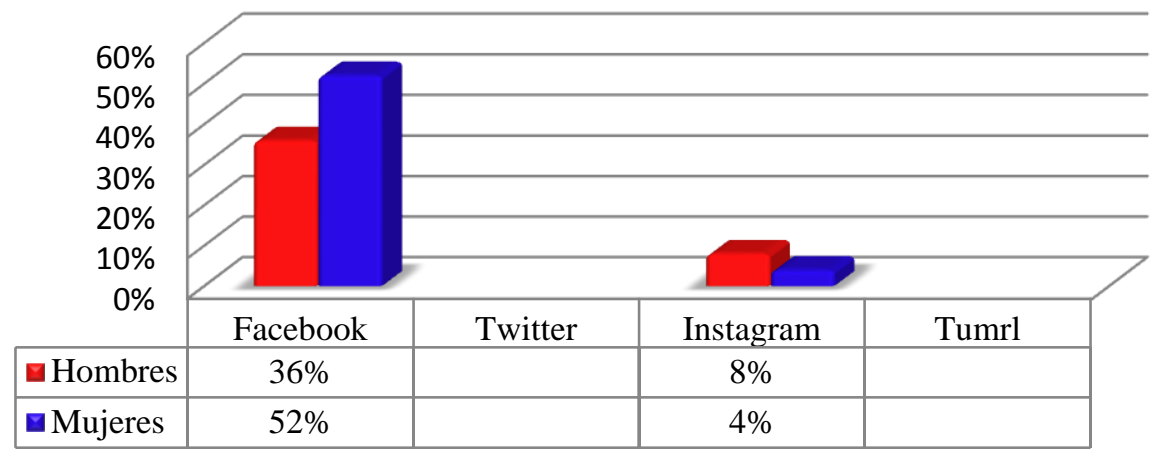

Gráfica 1. Distribución de promedios de las alternativas de la frecuencia del uso de las redes sociales

Tiempo de dedicación al uso de las redes sociales

La gráfica 2 demuestra que la mayoría de los estudiantes (mas varones, que hembras) dedican de 1 a 2 horas diarias a las redes sociales, mientras que otra parte, casi tan igual de grande de los estudiantes, dedican más de 4 horas a las redes sociales, dejando así una minoría de la población, que utiliza de 2 a 4 horas las redes sociales; por lo que queda evidenciado que son las mujeres quienes llegan a tener mayor imaginario colectivo; lo que nos trae como reflexión la importancia de un mayor control por parte de los padres del uso frecuente de las redes sociales, y de los maestro al buen uso de las mismas. Todo esto motivado a que los jóvenes distraen sus deberes y además pierden los buenos hábitos de estudios y lectura, que conlleva a su vez a que tengan mala ortografía al momento de redactar un trabajo o tomar un dictado.

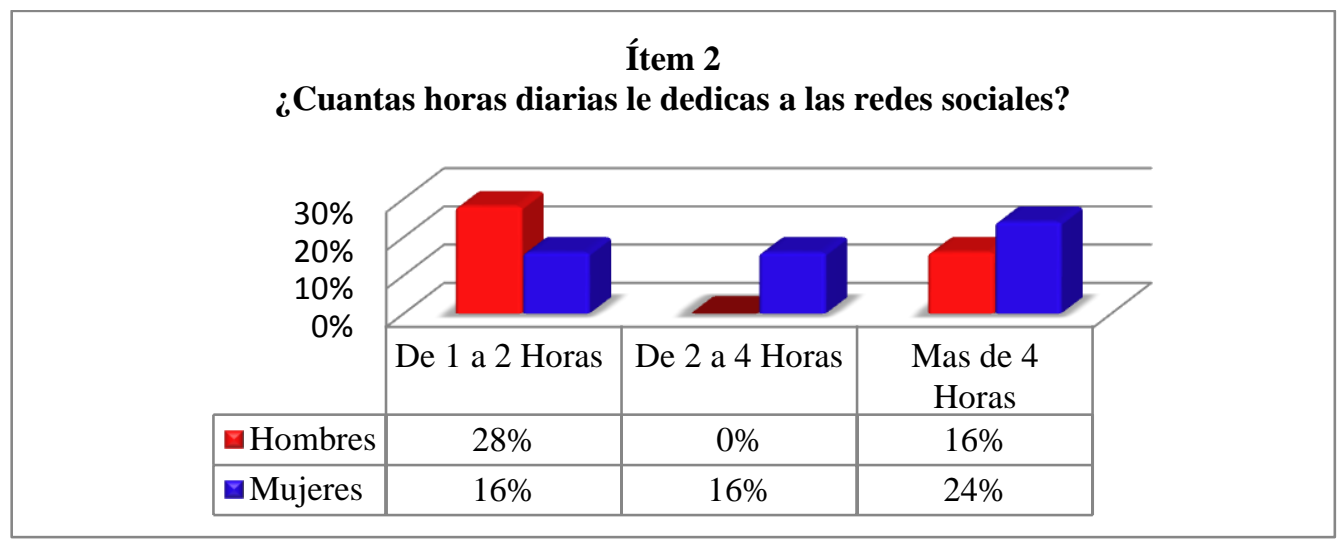

Gráfica 2. Distribución de promedios de las alternativas del tiempo del uso de las redes sociales 


\section{Distribución de promedios de las alternativas del uso de memes en las redes sociales}

En la gráfica 3 se puede determinar que los memes son parte de las conversaciones diarias de la mayoría de la población en la muestra encuestada, es importante destacar que los memes son utilizados más en las mujeres que en los hombres en el momento de realizar una conversación directa; lo que indica que las mismas no tienen un control adecuado por parte de los padres y representantes.

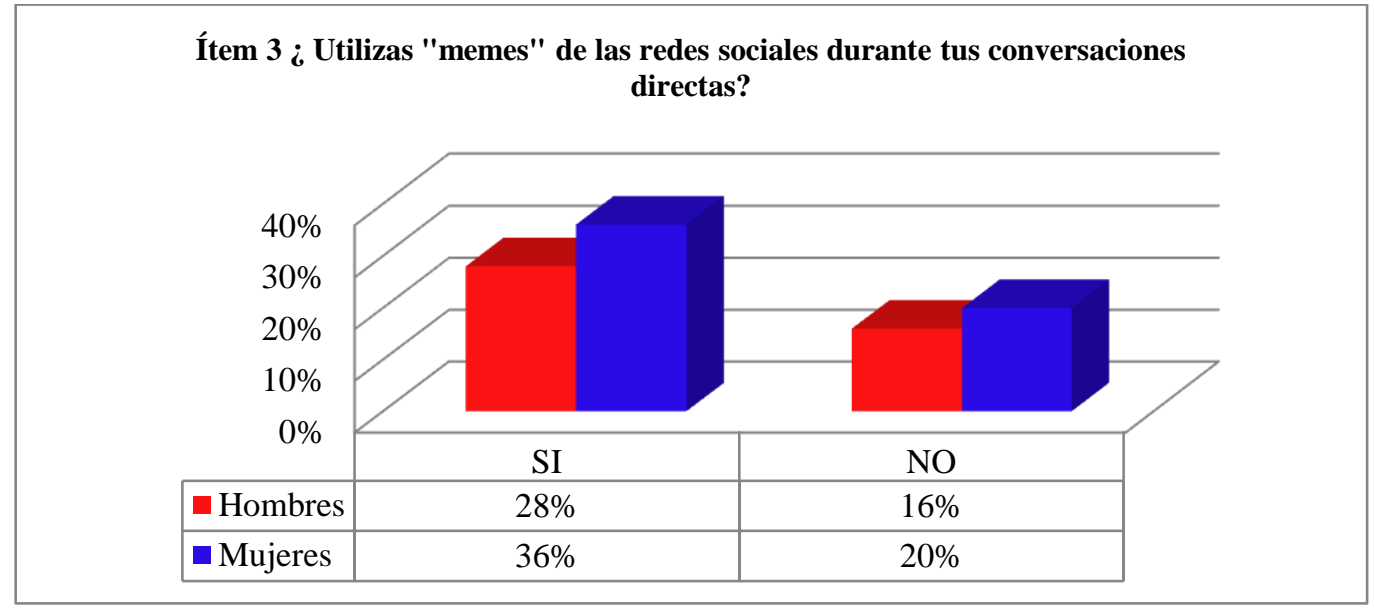

Gráfica 3. Distribución de promedios de las alternativas del uso de memes en las redes sociales

Uso de emoticones, caritas, figuras, signos o iconos en las conversaciones vías chat

Se determinó que la mayoría de la población estudiantil encuestada, utiliza caritas, emoticones, figuras, signos o iconos, en sus conversaciones diarias. Prevaleciendo como en las preguntas anteriores las mujeres. El uso de los mismos permite una mayor influencia en el imaginario colectivo y a la hora de un estudiante redactar un mensaje de texto todo lo quieren decir a través de imágenes de diferentes tipos, lo que acorta la buena redacción, la conversación fluida, el poco uso de los signos de puntuación y con esto van perdiendo buenos hábitos de estudio.

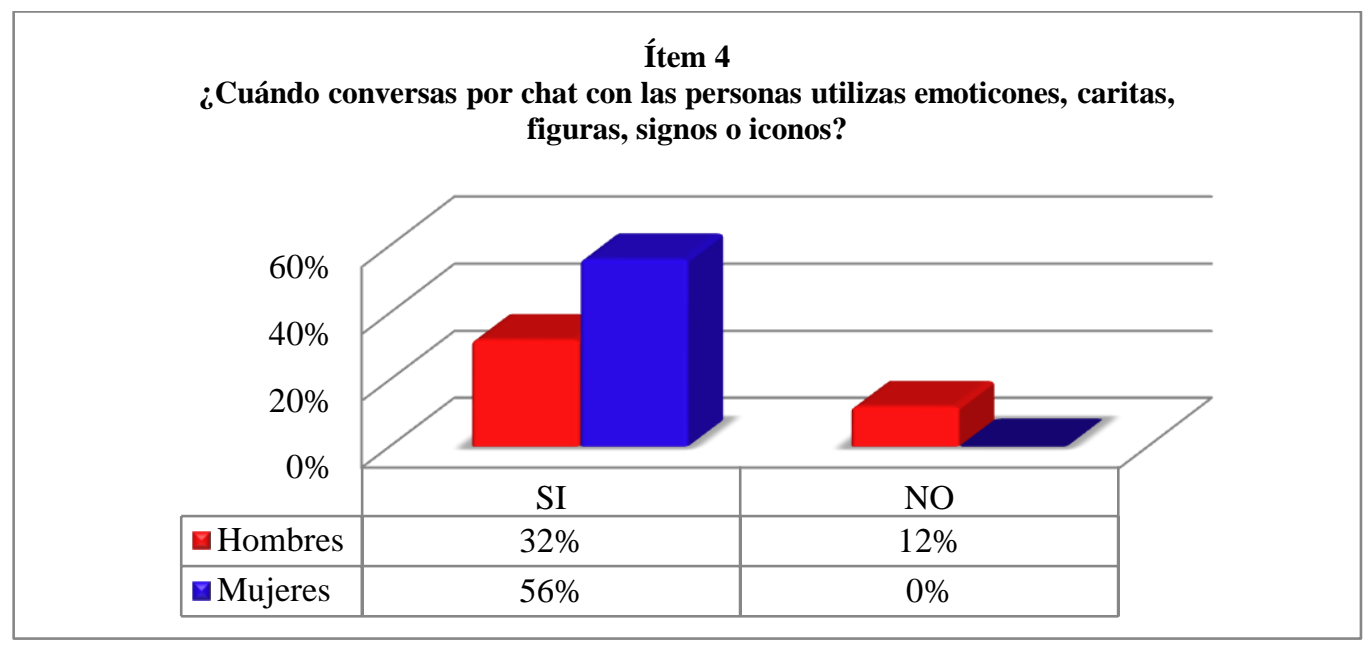

Gráfica 4. Distribución de promedios de las alternativas del uso de emoticones, caritas, figuras, signos o iconos en las conversaciones 


\section{Con relación a los motivos acerca del uso de Instagram}

Los estudiantes que utilizan la red social Instagram, dicen que lo hacen por mirar buenas fotos o videos. Sin embargo, en esta red social es el hombre quien prevalece en esta gráfica dando a entender que aunque no lo usa para comunicarse hay una influencia en el imaginario colectivo; lo que conlleva al estudiante a perder incluso la comunicación dentro del seno familiar, los buenos hábitos de estudio, entre otros que con el tiempo se pueden intensificar.

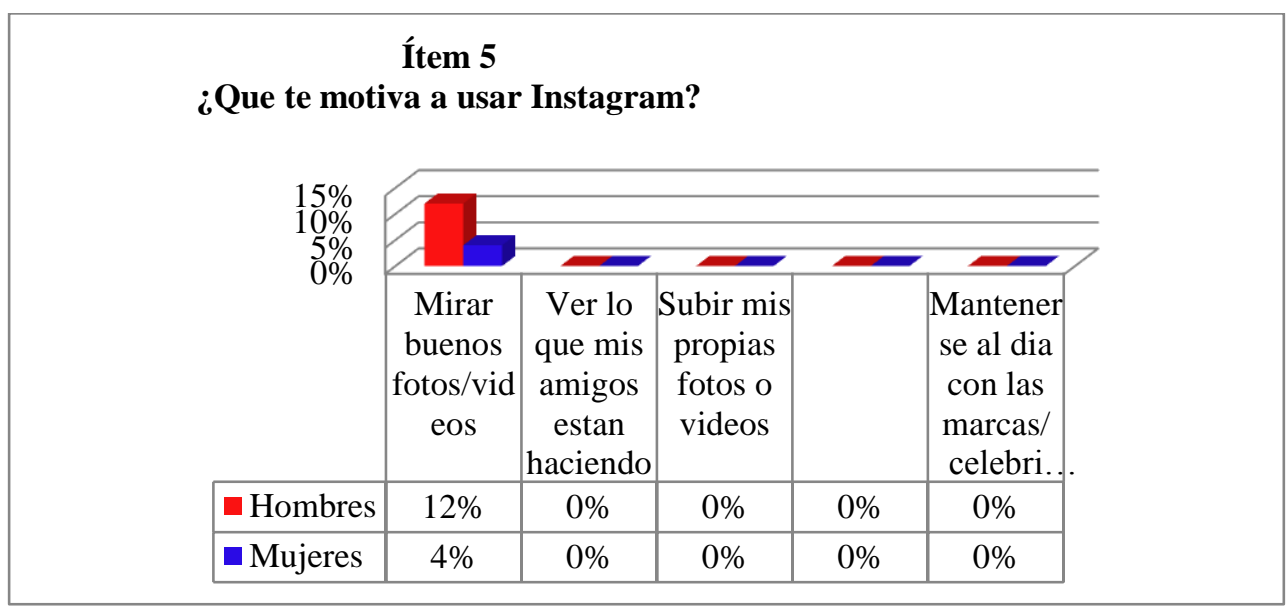

Gráfica 5. Distribución de promedios de las alternativas de motivación

\section{Discusión}

Las redes sociales forman parte de un instrumento para el consumo de la sociedad, teniendo en cuenta que no se tiene control de las mismas y siendo muy bien conocidas por la mayoría de los jóvenes, ellas mantienen una influencia sobre ellos de manera impresionante, son incluso instrumentos de publicidad efectiva, más que la televisión. Se puede decir que entre las redes sociales con más influencia están Facebook, Twitter, y uno de los más recientes Instagram, es por esto que el objeto de estudio, teniendo en cuenta que no se tiene control de los mensajes que los adolescentes envían y reciben por estos medios, se podría decir que las compañías de consumo se aprovechan de ello para hacerse publicidad.

Este planteamiento se realiza por la preocupación que se tiene por los jóvenes, ya que estas redes sociales buscan la estimulación de la satisfacción individual y no el promover el conocimiento y reflexión, teniendo en cuenta que pasan el mayor tiempo posible metidos en estas redes sociales que en el mundo real, existe la posibilidad de que estas redes sociales como el Instagram han ayudado a modificar el imaginario colectivo de los jóvenes, que las mismas han creado en ellos una fantasía de autocomplacencia e individualismo, teniendo relación con las imágenes y modelos que se exhiben en ellas, si a esto le sumamos la falta de supervisión y atención por parte de los padres y representantes, esto ha tenido sin duda un impacto en la conducta de nuestros jóvenes. Por estas razones fue analizada la influencia de la red social Instagram en los adolescentes.

A partir de los años 60 surgen múltiples teorías sobre los efectos sociales de los mensajes y representaciones de los medios, como la teoría de Edgar Morín que acuña el 
término de imaginario colectivo en el año 1960 (Gutiérrez y Noriega 2015)

Siguiendo la línea del tiempo, otra gran aportación es la de Jean Baudrillard (2018) en su libro Cultura Simulacro, es su concepto de Hiperrealidad con el que anula, no solo la realidad sino toda posibilidad de su existencia. A pesar de que para Baudrillard esta hiperrealidad es más que nada la sustitución de la misma por su imagen, por su máscara, por una construcción artificial de ella y en ese sentido pareciera no alcanzar ni siquiera el nivel de la virtualidad y quedarse en el mero plano de la ficción, la hiperrealidad se presenta como una realidad más real que la realidad pero además más atractiva y con mayor poder de seducción ya que ésta no es ya el reflejo, el clon o el holograma de lo real, sino la misma realidad perfeccionada, digitalizada, "photoshoppeada", cuya naturaleza acaba por sumir en el olvido a la realidad, que como dijera Baudrillard no es sino una perra. La Hiperrealidad es no solo un fenómeno de la posmodernidad, el producto de una operación de hipérbole, es también una categoría analítica que trasciende el campo de la comunicación y la filosofía y es esencialmente un elemento de análisis transdisciplinario y dinámico.

Tal como plantea Gallego (2016) la Red Social Instagram cuenta con más de 900 millones de usuarios activos, en donde la cuenta oficial de Instagram cuenta con 269 millones de seguidores, su función es subir fotos y videos. Los usuarios también pueden aplicar efectos fotográficos como filtros, marcos, similitudes térmicas áreas subyacentes en las bases cóncavas, colores retro, y posteriormente compartir las fotografías en la misma red social o en otras. Generalmente estos usuarios crean unas series de imágenes editadas que por lo general incluyen una frase graciosa, que generan un tipo de manifes-tación cultural, estas imágenes que pueden llegar a propagarse de persona en persona y de comunidad en comunidad, es decir, lo que hoy se conoce en internet como tendencia.

Estas series de imágenes propagadas por los usuarios de Instagram van formando en esta comunidad dentro de su dimensión imaginaria un conjunto de símbolos y mensajes, creando así una tendencia y a su vez volviéndose mayoritaria por el grupo de personas, del cual comparte esa series de imágenes e ideas, también crean imágenes de acuerdo a esa tendencia, que va modificando la dimensión real y gradualmente se vuelve una hiperrealidad con el que anula, no solo la realidad sino toda posibilidad de su existencia y que enmudecen a la minoría que está en desacuerdo o tienes posiciones diferentes a la mayoría con dichas imágenes que propagan esas ideas.

Por la realización de estas manifestaciones culturales, como afirma Castells (2009) cada persona puede construir su red de redes de comunicación, él plantea que el cambio cultural en el mundo globalizado, para que haya comunicación, emisores y receptores antes de tener códigos comunes en el negocio de los medios de comunicación, se ha producido un cambio estratégico que ha llevado que de la difusión a una audiencia genérica a una audiencia concreta, esto ha sido posible a la conexión de red en empresas globales de comunicación y en las nuevas tecnologías digitales que permiten combinar producción masiva y distribución personalizada de contenidos para identificar a la audiencia, es necesario comprender sus distintos códigos culturales.

Por lo tanto, la evolución del formato y del contenido depende netamente de la evolución cultural en la sociedad, en la que podemos apreciar tres niveles, en primer lugar, para la reducida pero influyente minoría de gente existe la conciencia de un destino común del planeta que habitamos, en segundo 
lugar, hay una cultura global multicultural que se caracteriza por la mezcla de culturas de distintos orígenes y por último la que quizás sea la capa fundamental de la globalización cultural, es la cultura del consumismo directamente relacionada con la formación de un mercado capital global.

El proceso de transformación cultural en nuestro mundo evoluciona a lo largo de dos ejes, la oposición entre globalización e identificación y la brecha entre individualismo y comunalismo, de la interacción de las dos grandes tendencias culturales que caracterizan a la sociedad red global, han surgido cuatro configuraciones culturales, consumismo representado por las marcas, individualismo en red, cosmopolitismo ya sea ideológico, político o religioso y multiculturalismo estos son los modelos básicos culturales de la sociedad red global y este es el espacio cultural en el que debe funcionar el sistema de comunicación.

A través de este proceso de transformación cultural, en la red social Instagram debido a la propagación de series de imágenes, pueden crear prejuicios en cual incluye sentimientos de desprecio o desagrado de miedo y aversión, así como varias formas de conductas hostiles a personas, ya sea sobre su ideología, político o religioso de la sociedad red global, esto conlleva en que el estudiante puede que tenga errores de percepción de una cultura. Basándonos en los principios de los 7 Saberes de Edgar Morín (2001), podemos enseñar un conocimiento capaz de criticar el propio conocimiento en este sentido desvelando el contexto, lo global, lo multidimensional y la interacción compleja. Sabiendo que la complejidad como lo plantea Edgar Morin (1990), no es un fundamento, es el principio regulador que no pierde nunca de vista la realidad del tejido fenoménico en la cual estamos y que constituye nuestro mundo. Se ha hablado también de monstruos, y yo creo, efectivamente, que lo real es monstruoso. Es enorme, está fuera de toda norma, escapa, en última instancia, a nuestros conceptos reguladores, pero podemos tratar de gobernar al máximo a esa regulación.

Debido a lo planteado, el objetivo general es analizar la Influencia de la red social "Instagram" en la configuración de un nuevo imaginario colectivo entre los adolescentes del Liceo Abdón Calderón del Municipio Naguanagua del Estado Carabobo, destacado en el IV Principio de Identidad Terrenal de Edgar Morin en su libro los 7 saberes necesarios para la Educación en el futuro (2001), donde afirma que la organización de un todo produce cualidades o propiedades nuevas en relación con las partes consideradas de forma aislada, de manera que para comprender cualquier fenómeno o acontecimiento hay que estudiar las partes y el todo al mismo tiempo, ya que los cambios que se produzcan en los elementos constitutivos originarán cambios a nivel general.

Con las aportaciones teóricas presentadas y articuladas en esta investigación contribuirán como base sólida con relación a los objetivos planteados de como configura la Red Social Instagram en el imaginario colectivo y el proceso comunicativo en los estudiantes de secundaria del Liceo Abdón Calderón.

\section{CONCLUSIONES}

Para dar respuesta y análisis al primer objetivo denominado "describir como el uso de la red social Instagram ha coadyuvado en el surgimiento de un nuevo imaginario colectivo cultural entre los jóvenes entre los 12 y 16 años del U.E. Abdón Calderón, del Municipio Naguanagua del Estado Carabobo"; los resultados nos describen que la red social Instagram no influye tanto como el Facebook 
a pesar de que ambas pertenecen al mismo dueño, lo que nos hace pensar que esto puede darse por el tipo de formato con el que la red Facebook es creada en donde se puede visualizar una gran variedad de aplicaciones que les permite a los jóvenes no solo compartir imágenes sino también memes, hacer uso del chat dentro de la misma página principal dándole además uso a los emoticones, gif entre otros, además contiene juegos en línea, entre otras características que lo hacen más atractiva.

Con respecto al segundo objetivo, el cual es "determinar el impacto que posee el uso continuo de la red social Instagram en el proceso comunicativo entre los jóvenes entre los 12 y 16 años del U.E. Abdón Calderón, del Municipio Naguanagua del Estado Carabobo. Los resultados determinaron que un alto porcentaje de estudiantes no hace un mayor uso de la red social Instagram por lo que se puede determinar que no tiene un impacto social y cultural en los jóvenes de la U.E. Abdón Calderón del Municipio Naguanagua. Es importante destacar que el imaginario colectivo en estos jóvenes está determinado por el uso de otras redes sociales en donde predomina el Facebook y se pudo observar además que la misma es utilizada más por las hembras que por lo varones.

En tal sentido, el logro de los dos objetivos específicos permitió dar respuesta al objetivo general de esta investigación el cual es "analizar la influencia que ejerce la red social Instagram en la configuración de un nuevo imaginario colectivo de los estudiantes del Liceo Abdón Calderón", concluyendo que existen otras redes sociales (Facebook) que si influyen de forma más directa en la configuración de un imaginario colectivo.

Unas vez analizada la realidad existente en el uso de la red social Instagram se pudo determinar que el nivel de uso de la misma no es tan influyente como la red social Facebook en el imaginario colectivo de estos adolescentes objeto de estudio ya que gran parte de los mismos de mayor uso a esta red social y no al Instagram, quizás por la variedad con la que la red social Facebook fue creada; también es importante destacar que la misma es más utilizadas por hembras que por los varones.

Ante el anterior análisis recomendamos a las Familias que se debe orientar el uso de las redes sociales en los jóvenes procurando que ellos tengan otras formas de distracción tales como los deportes u otras ocupaciones de índole cultural o académica. La familia debe supervisar el uso que le dan sus hijos a las diversas redes sociales a fin de estar atentos en que herramientas usan y como la usan, para ello es muy importante establecer conversaciones sinceras y francas con sus hijos y hacerles ver lo positivo y lo negativo de las redes sociales y mantener mayor comunicación y motivación hacia la lectura y escritura ya que las mismas le ayudan a mejorar la redacción, la ortografía, caligrafía, uso correcto de los signos de puntuación, enriquecimiento del vocabulario, entre otros.

A los docentes y orientadores les recordamos que es importante que siempre esté actualizado en el uso de las redes sociales ya que ellos cumplen un papel importante en el uso de las mismas, e indagar cada cierto tiempo con los estudiantes que les parece el uso de las redes sociales, que opinan de ello y para que las usan.

Es muy importante promover charlas orientadas a la familia en función del buen uso de las rede sociales integrando la familia en las diversas actividades que se realicen referentes al uso de las ventajas y desventajas del uso de las redes sociales, realizando video foros para el buen del uso de las redes sociales. 


\section{REFERENCIAS}

Baudrillard, J. (2018) Hiperrealidad y simulacros Recuperado de https://debedehaber.wordpress.com/20 15/01/14/hiperrealidad-y-simulacrossegun-jean-baudrillard-2/

Castells, M (2009) Comunicación y poder Recuperado de https://evpubli.unileon.es/index.php/pol igonos/article/viewFile/404/358

Gallego, S. (2016) Redes Sociales Digitales: información, comunicación y sociedad en el siglo XXI (2000-2010) Madrid, España Universidad Complutense de Madrid,

Gutiérrez. C. y Noriega, P. (2015) Estudio interpretativo del uso excesivo de las redes sociales a través de relatos de vida en jóvenes con edades comprendidas entre los 21 y 23 años Valencia Universidad de Carabobo, Carabobo, Venezuela

Morín, E. (1990). Introducción al Pensamiento Complejo. España: Gedisa Editorial.

Morín, Edgar. (2001). Los siete saberes necesarios para la educación del futuro. Bueno Aires, Nueva Visión.

Torres, M. (2017) Instagram y su uso como una herramienta de marketing digital en Chile Santiago Universidad de Chile 